\title{
COMPUTATIONAL DYNAMICS OF A LIGHT AIRPLANE
}

\section{P. Chudý, V. Daněk}

Institute of Aerospace Engineering, Brno University of Technology, Technická 2, Czech Republic. E-mail: peter.chudy@pobox.sk; danek@fme.vutbr.cz Received 0702 2005, accepted 06032006

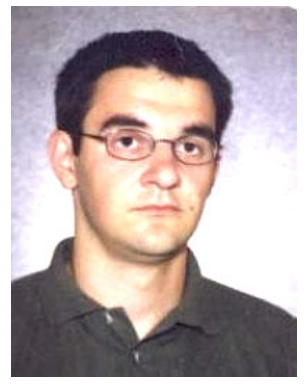

Peter CHUDÝ, PhD student

Education: 2001 - Brno University of Technology, Institute of Aerospace Engineering.

Affiliations and functions: Since 2001 - Ph.D. student - Institute of Aerospace Engineering, Brno University of Technology.

Experience: 2001-2002 CFD analysis of Nacelle turboprop engine; 2002-2004 computational flight dynamics, estimation of aeroelastic response.

Present position: $\mathrm{PhD}$ student at the Institute of Aerospace Engineering, Faculty of Mechanical Engineering; Brno University of Technology; Technická 2, 61669 Brno, Czech Republic; Tel.: +420 541143370.

Vladimír DANĚK, Assoc Prof

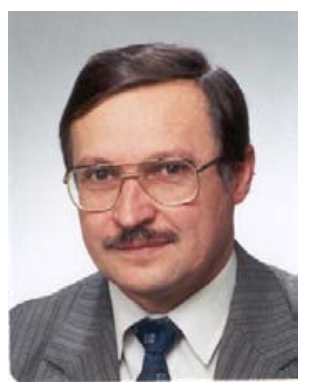

Education: 1970 - Faculty of Aviation, Military Academy of Brno, M.Sc. (Eng.) 1970, Ph.D. 1981, Assoc. Prof. 1986.

Affiliations and functions: LET Kunovice - Aerodynamicist (1970-1974); Military Academy of Brno, Faculty of Aviation Engineering - Lecturer of Aircraft Design (1974-1983); Brno University of Technology, Faculty of Mechanical Engineering (FME), Institute of Aerospace Engineering (IAE) - Senior Lecturer (from 1983), Vicedean of FME (1991-1994).

Professional memberships: Member of the Czech Society for Mechanics at the Academy of Sciences of the Czech Republic; Member of Technical Committee of Czech Aeroclub.

Experience: Aerodynamics and flight mechanics research and development worker since 1970; teaching aircraft design, aerodynamics, flight mechanics, aeroelasticity, flight testing; test pilot qualification for glider and motor glider.

Present position: Senior Lecturer of Flight Mechanics, Vice-director of IAE, Head of Flight Research and Testing Group of IAE, Faculty of Mechanical Engineering, Brno University of Technology, Technická 2, 61669 Brno, Czech Republic; Tel.: +420 541142229.

\begin{abstract}
This paper presents work performed by the Institute of Aerospace Engineering at the Brno University of Technology. The main purpose of the project was to compare the results obtained from complex numerical simulation and analytical solutions of the aeroelastic response of an airplane. Numerical simulations provide a integrated description of the dynamic processes analyzed and monitoring of selected quantities in the time domain. This represents a tool for the visual qualification of the investigated process. Utilization of a simplified beam-stick model represents an industrial standard in the field of computational aeroelasticity/flight mechanics. The need for complex aeroelastic simulations leads to a concept of an advanced aeroelastic model that integrates an advanced 3D dynamic part (model) with proven aerodynamic theory.
\end{abstract}

Keywords: computational aeroelasticity, computational flight mechanics, dynamic response estimation, finite element model, unsteady aerodynamics, advanced modeling techniques, flying qualities.

\section{Introduction}

The aim of aeronautical engineers to design optimized lightweight vehicles led to slender wing design, which in turn imposed new problems in airplane dynamics. The estimation of dynamic response qualities thus became an important engineering task. Prior to numerical simulation, all estimations were done using data derived from flight measurements of airplanes already built. Modern concepts utilize proven computational methods and combine them to create a virtual representative of the investigated system. The necessity to extend dynamic analysis beyond the classical approaches arose from the changing requirements for aeronautical structural design motivated mainly by advances in aerodynamics and material sciences. Slender wings are more likely to be subjected to larger deformations, thus leading to potential load redistributions and variations in dynamics resulting in changes of handling qualities. 


\section{Computational flight mechanics}

Generation of a mathematical model representing the investigated system under operational conditions is a task belonging to flight mechanics that includes aeroelastic. The interdisciplinary nature of aeroelasticity combines specific fields of structural dynamics, aerodynamics, and elasticity. An aeroelastic model, as a virtual representative of an elastic system exposed to external aerodynamic loading, consists of two major submodels - the first comprises dynamic characteristics (usually designated "dynamic" or elasto-inertial model). The second represents aerodynamic forces acting on the structure (referred as the aerodynamic model). Interpolation techniques used to transfer loads and displacements between dynamic and aerodynamic part play a critical role in the modeling process $[10,4,1]$.

The intention of the extended research is to pursue the area of classical aeroelastic computation and put it further towards modeling of aircrafts flying qualities, stability and control - in other words - mathematical modeling of elastic aircraft flight dynamics.

The description of unsteady aerodynamic forces acting on the structure still represents the biggest challenge in the process of creating a reliable aeroelastic model. The more straightforward the model's physical boundaries, the more complicated the fluid description is. Traditionally, various panel methods have been used to estimate the aerodynamic characteristics. From certain points, the panel methods seemed to be aged and not sophisticated enough to be further implemented.

Compared to the more advanced finite volume algorithms, however, the panel methods still offer reasonable results without the time, storage, and computational penalty. Application of specific mathematical concepts for aerodynamic loading estimation underlines the need for careful consideration of modeled flight conditions. Panel methods based on the potential flow theory are not able to capture flow separation effects frequently occurring during maneuvers at lifting surfaces. To capture the effects of flow nonlinearities corrective methods need to be implemented.

Utilization of aerodynamic modeling techniques based on panel methods relies heavily on their time efficiency and overall simplicity. Even though advanced coupling methods to join complex structural and aerodynamic model have been developed, implementation of a less sophisticated couple was found suitable for the initial research attempt.

A generally accepted illustration of classical aeronautical structure was projected to the simplified beam model. Long slender wings, tubular fuselages, monocoque or semi-monocoque structures allowed beams with varying cross section instead to be used of complex 3D bodies. These simplifications proved to be adequate for some groups of computational tasks. The idea behind using a more complex structural representative finds its roots in the search for one advanced model, which could be used for several sets of tests, ranging from simple static loadings to dynamic maneuver response evaluations. The more complex the description of the model gets, however, the more obstacles can be expected in the computational process. The complex geometry of an airplane modeled in terms of finite elements tends to create significant concerns in the modal analysis part of the computational process where parasitic vibration modes may accompany the process. Even the simple "beam" representative can be treated by some straightforward techniques; its complex counterpart is basically sentenced to the very own idea of complex modeling.

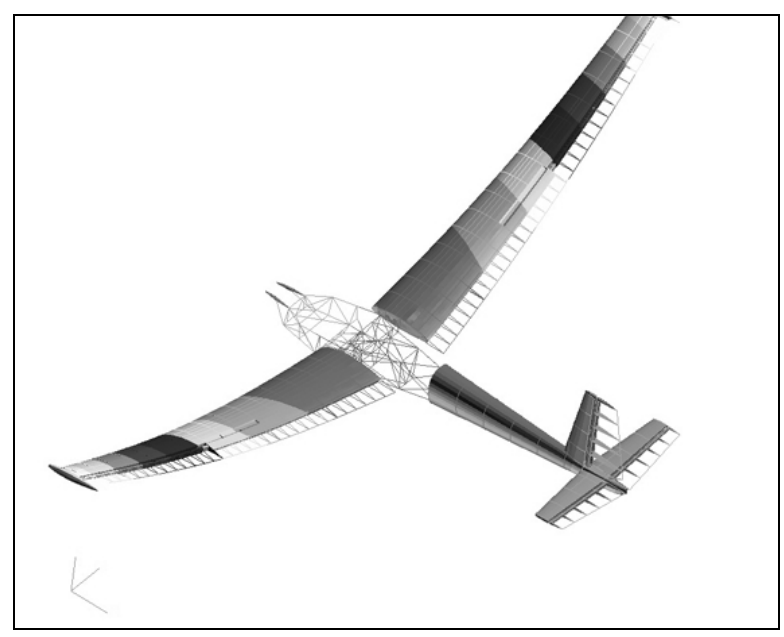

Fig 1. Modal analysis $-1^{\text {st }}$ symmetric bending

This technique covers all significant details that can be found in the structure, thus limiting the area of possible misjudgments.

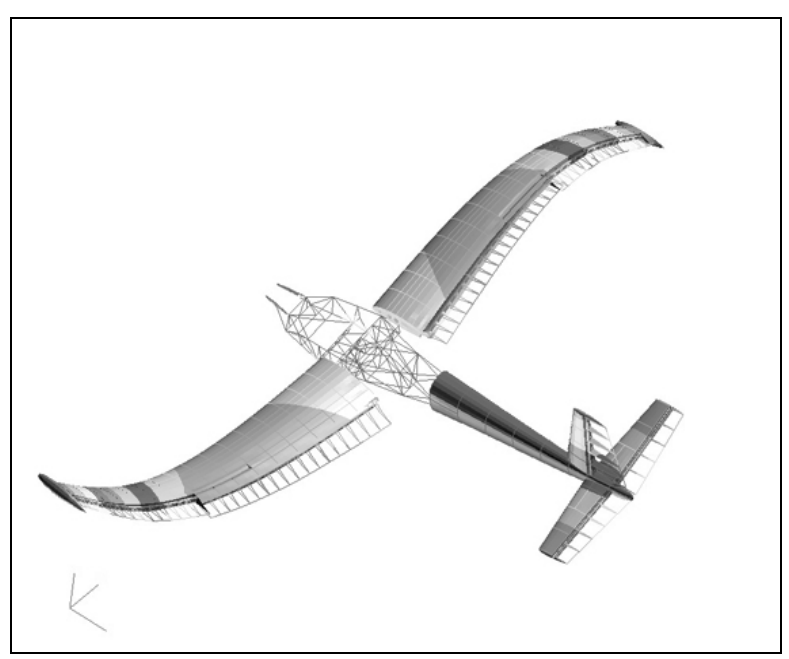

Fig 2. Modal analysis $-1^{\text {st }}$ antisym. bending

Considerations of all major structural elements surrounded by additional structural details should offer a relatively solid basis for modal-based computational approaches. To avoid the occurrence of "noise" in the form of parasitic vibration modes, the main modeling process focuses on the primary structure, "limiting the presence" of the non-stressed parts. 
The term "overseeing" is limited to the extent of neglecting load carrying capability and substituting geometrical and inertial properties into simpler forms.

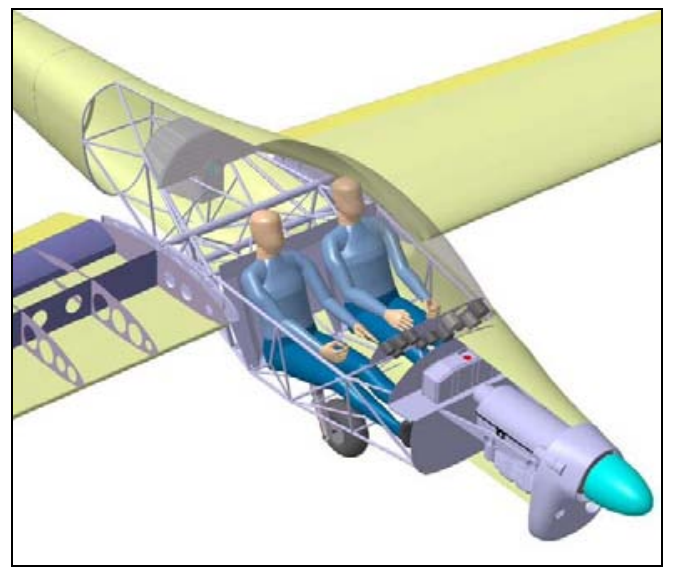

Fig 3. CAD model

The main purpose was to create a realistic dynamic model while considering all the restrictions in computational capacity and the "time" dimension of the problem. Using simplified representatives of parts that are of secondary interest accelerates the own computational phase.

\section{Modeled aeroelastic system}

The investigated system is a side-by-side two-seat powered glider. The fuselage features a fully equipped two-seat cockpit. Its rear part consists of a longeron stiffened semi-mocoque structure. The metallic wing is equipped with ailerons and landing flaps. According to its conventional design, it features a main spar and an auxiliary spar as load carrying elements. Sufficient structural stiffness was achieved by adding a system of stringers. The metallic stressed skin is attached to the system of ribs and spars using riveting technology. The tail unit was designed following the same principles.

\section{FEM dynamic model}

Figure 3 shows the resulting MSC/NASTRAN finite element full span model used in the analysis. The complex model integrates all major airframe structural components. The model mass is continuously distributed over the entire structure. In special cases involving masses of non-load carrying elements, these were substituted by concentrated masses respecting their actual physical position on the airplane.

Control surfaces and high lift devices have been modeled as separate features using the same principles vital for the original structure. This can also be seen in Figure 3. The structural mesh of the wing includes elements representing the main and auxiliary spars, ribs, skin panels, and individual groups featuring ailerons and landing flaps.
The structural design of control and high lift devices has a common classical core. The control surfaces and landing flaps are covered with non-stressed fabric and their load carrying capability was thus neglected.

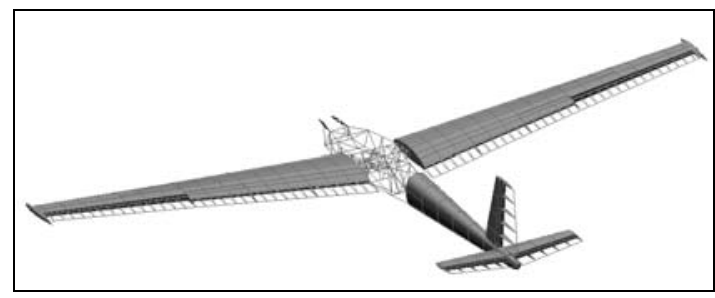

Fig 4. FEM model

\section{Aerodynamic model}

The aerodynamic conditions are defined by Doublet-Lattice Method (DLM). The wing was divided into dorsal and ventral parts. The horizontal and vertical tails also feature aerodynamic panels. Separate aerodynamical panes have been added to the control surfaces and high lift devices.

The theoretical basis of the DLM, used to compute the unsteady aerodynamics, is linearized aerodynamic potential theory. All lifting surfaces are assumed to lie parallel to the flow $[8,3]$.

The modal displacements of aerodynamic boxes are related to displacements of the structural grids by a surface splining technique. The aerodynamic theory (DLM) used in this case does not allow the definition of camber, twist, or angle of incidence.

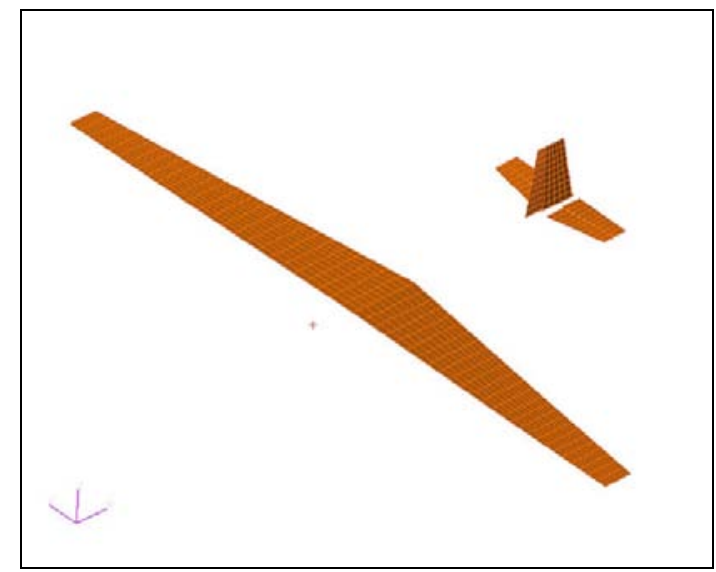

Fig 5. Aerodynamic panels

\section{Response to aileron input}

The estimation of the response parameters is an important part of the design processes. Conventional analytical methods support procedures derived to predict flying qualities and performances of rigid aeronautical structures. The main goal of the computational process was to estimate Lateral Directional Stability derivatives from the results of dynamic numerical simulation. The input signal of a square shape subjected the aircraft to 
rotate around its longitudinal axis. Aileron input of 0.25 sec. duration featured $15 \mathrm{deg}$. deflections in both directions.

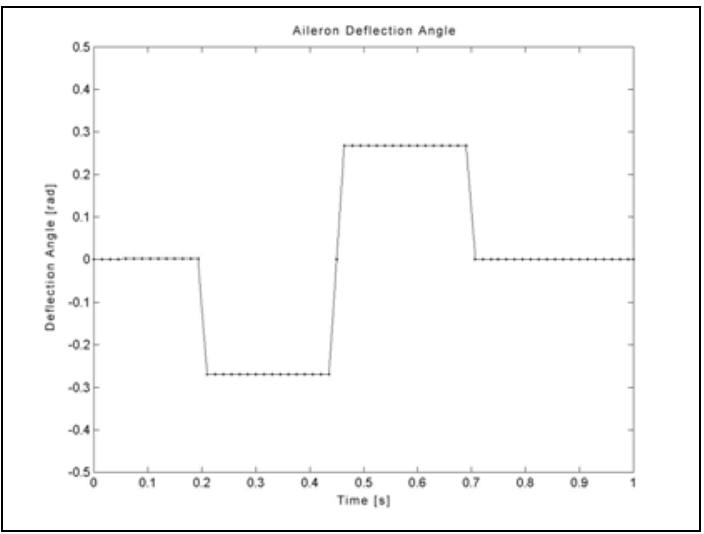

Fig 6. Aileron input signal

This complies with the small disturbance theory assumption used as theoretical basis for our computations. The quantities investigated were steady roll rate coefficients and related stability derivatives. After running the simulation, we were able to obtain a time history of monitored quantities. Since our interest was oriented towards the estimation of flying characteristics resulting from aileron, input a roll angle time history represented the desired data source used for subsequent processing. Additional mathematical operations were used to extract steady roll rate and stability derivatives $[7,5]$.

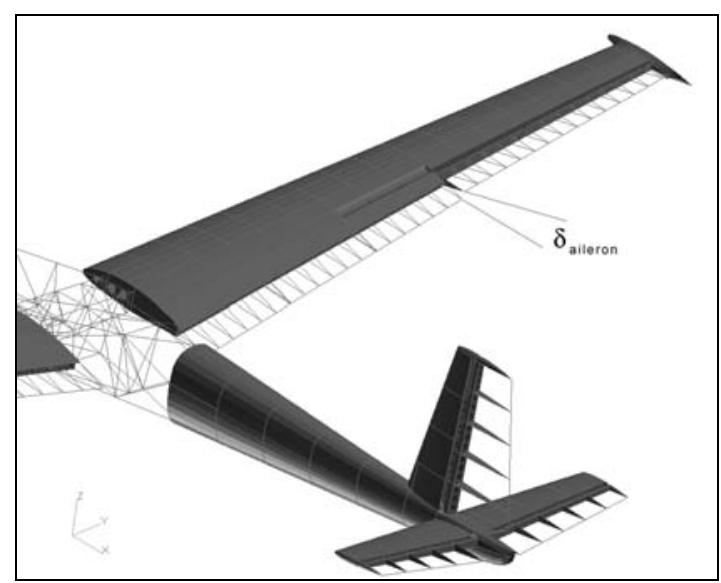

Fig 7. Aileron deflection

A curve representing the change of roll angle as a function of time (or in other words - the roll rate) was added to the graph of computed roll angle time history in order to compare the results obtained from numerical simulation with those based on conventional analytical approach. Regarding the curves' slope similarity, we can point at the suitability of the numerical procedure at the field of light aircraft design. Estimation of the stability derivative ratio was based on the knowledge of the steady roll rate due to aileron deflection. The roll rate value was obtained from the slope of computed roll angle time history.

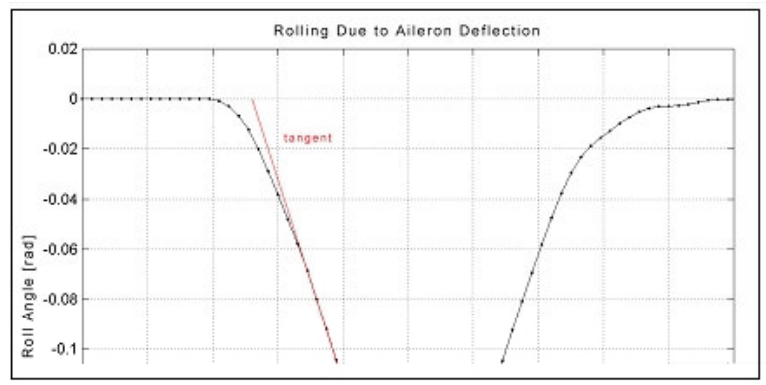

Fig 8. Roll angle time history

The following lines show the procedure used to estimate the non-dimensional ratio of stability derivatives based on the results obtained from complex numerical simulation:

$$
\begin{aligned}
\frac{C_{l \delta}}{C_{l P}} & =\frac{p \cdot l}{2 \cdot V \cdot \delta_{\text {aileron }}} \\
\frac{C_{l \delta}}{C_{l P}} & =-0.6256[1]
\end{aligned}
$$

The non-dimensional ratio of the stability derivatives was also obtained by utilization of an analytical approach using time-proven graphs and tables for following flight conditions:

Table 1. Flight conditions

\begin{tabular}{|l|l|}
\hline Altitude & $1000.0 \mathrm{~m}$ \\
\hline True Air Speed (TAS) & $44.0 \mathrm{~m} . \mathrm{s}^{-1}$ \\
\hline Dynamic Pressure & $1076.06 \mathrm{~Pa}$ \\
\hline Aileron Deflection & $15 \mathrm{deg}$ \\
\hline
\end{tabular}

By comparing the results of both estimation procedures, we can see the same level of "good match" as was in the case of roll rate calculation.

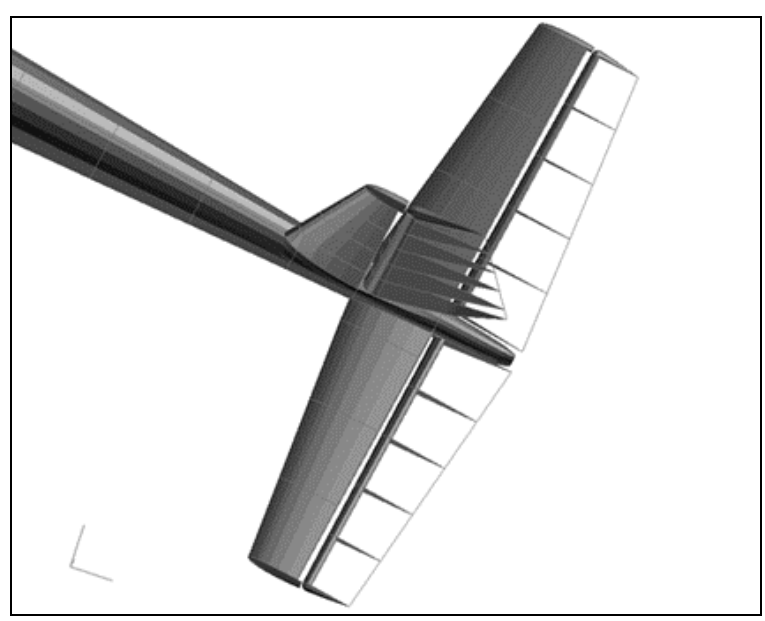

Fig 9. Rudder deflection 
Table 2. Comparison of results

\begin{tabular}{|c|c|}
\hline Analytical solution & Dynamic solution \\
\hline$-0.6237[1]$ & $-0.6256[1]$ \\
\hline
\end{tabular}

A similar technique can be used to monitor responses due to pilot inputs to the remaining control surfaces (rudder or elevator). The following picture shows rudder deflection during one of the computational stages.

\section{Conclusion}

An early assumption regarding the "rigidity" of the investigated system was later confirmed by the results of the simulation process. The "conventional" analytical solution and the "competing" mathematical simulation are complementary tools in the process of estimating the flying quantities of light aircraft.

Complex structural models can be further advantageously used for optimization purposes as well as for other types of structural analysis. The complex scope of detailed modeling returned in the form of highly illustrative results.

\section{References}

1. Bisplinghoff R.L., Ashley, H., Halfman, R.L. Aeroelasticity. - New York: Dover Publications, 1996.

2. CS-22: Sailplanes and Powered Sailplanes. -2001.

3. Eight NASTRAN User's Colloquium, NASA-CP2131. Greenbelt, Maryland, October 1979. - 1979.

4. Hodges D. H., Pierce G. A. Introduction to Structural Dynamics and Aeroelasticity // Cambridge Aerospace Series. - 2002.

5. McCormick B.W. Aerodynamics, Aeronautics and Flight Mechanics. - New York: John Wiley \& Sons, Inc., 1979.

6. Naser A.S., Pototzky A.S., Spain C.V. Response of Alliance 1 Proof-of-Concept Airplane Under Gust Loads. NASA/CR-2001-210649. - 2001.

7. Pamadi B. Performance, Stability, Dynamics, and Control of Airplanes. AIAA. - 2004.

8. Rodden, W.P., Johnson, E.H. MSC/NASTRAN Aeroelastic Analysis User's Guide. - Los Angeles: The MacNeal Schwendler Corporation ,1994.

9. Stevens L.B., Lewis F.L. Aircraft Control and Simulation. - John Wiley \& Sons, Inc., 2003.

10. Waszak M.R., Buttrill C.S., Schmidt, D.K. Modeling and Model Simplification of Aeroelastic Vehicles: An Overview, NASA Technical Memorandum 107691. - 1992.

\section{Nomenclature}

$\begin{array}{ll}M & \text { Mach number } \\ p & \text { Steady roll rate } \\ H & \text { Altitude } \\ \rho & \text { Air density } \\ V & \text { Airplane velocity } \\ S & \text { Design wing area } \\ \delta_{\text {aileron }} & \text { Aileron deflection } \\ l & \text { Wing span } \\ C_{l P} & \text { Roll damping coefficient } \\ C_{l \delta} & \text { Rolling moment due to aileron derivative } \\ C A D & \text { Computer Aided Design } \\ D L M & \text { Doublet Lattice Method } \\ F E M & \text { Finite Element Method }\end{array}$

